\title{
Permeability and Tensile Strength of Concrete with Arabic Gum Biopolymer
}

\author{
Abdeliazim Mustafa Mohamed, ${ }^{1,2}$ Mohd Hanim Osman, ${ }^{1}$ Hichem Smaoui, ${ }^{2}$ \\ and Mohd Azreen Mohd Ariffin ${ }^{1}$ \\ ${ }^{1}$ Faculty of Civil Engineering, Universiti Teknologi Malaysia, Johor, Malaysia \\ ${ }^{2}$ College of Engineering, Prince Sattam Bin Abdulaziz University, Al-Kharj, Saudi Arabia
}

Correspondence should be addressed to Abdeliazim Mustafa Mohamed; mmabdeliazim2@live.utm.my

Received 26 April 2017; Accepted 17 July 2017; Published 15 August 2017

Academic Editor: Ghassan Chehab

Copyright (C) 2017 Abdeliazim Mustafa Mohamed et al. This is an open access article distributed under the Creative Commons Attribution License, which permits unrestricted use, distribution, and reproduction in any medium, provided the original work is properly cited.

\begin{abstract}
The use of materials of vegetal origin is increasingly being promoted in many industries due to their cost effectiveness and the rising sensitivity to environmental protection and sustainability. Arabic Gum Biopolymer (AGB) is a wild plant byproduct that is abundantly found in Sudan and is also produced in other African countries. It has long been used in various industries. However, its utilization is very limited in the construction sector although there appears to be a significant potential for use of AGB in the building industry. As an example, there is evidence that AGB may be an effective additive to concrete mixes that would improve fresh and hardened concrete properties. The aim of the present work is to provide further experimental evidence on the improvement that can be achieved in the physical and mechanical properties of hardened concrete when AGB is added to the mixture. The experimental results show a significant reduction in permeability for an optimum percentage of AGB and an increase in flexural and tensile strength and in the elastic modulus.
\end{abstract}

\section{Introduction}

Sustainable materials are increasingly sought after as alternatives to traditional products in all industrial sectors. Wild plant derivatives, when exploited in reasonable amounts, constitute a valuable source of such sustainable materials. Arabic Gum Biopolymer (AGB), an abundant wild plant product found mainly in Sudan $(70-85 \%$ of world production) [1] and in other tropical African countries, is known for its low viscosity and high solubility in water [2]. For these desirable properties, it has been used in many industries including textiles, cosmetics, lithography, pharmaceuticals, encapsulation, and even the food industry. Procurement processes for AGB are therefore already in place for the supply of these sectors.

It is noted, however, that, apart from a few exceptions, AGB is underused in the construction sector. The few exceptions include its use in the composition of certain paints or, as reported in [3], of binders to ceramic glazes in order to improve the adhesion of the clay to the glaze before it is heated. Besides the merit of sustainability, Arabic Gum Biopolymer benefits the local communities in producing countries through employment of a large segment of the population in the collection, extraction, and distribution of AGB. Creating new outlets for the product would induce social and economic impacts. Being a huge consumer of materials the construction industry would constitute a large market for AGB if applications thereof were identified.

In a recent work [4], the effect of adding AGB dissolved in water in concrete mix on the properties of ordinary concrete was investigated. The study concluded that Arabic Gum provides better workability and higher compressive strength.

Compressive strength is reported in [5] to be reduced by the replacement of some amount of cement by rice husk ash (RHA) up to $10-20 \%$ while the porosity and capillarity are increased and the slump lies in the range $80-100 \mathrm{~mm}$ [5].

The permeability of concrete is affected by the replacement of fly ash with foundry sand [6]. The minimum of permeability was found at $30 \%$ of fly ash. Later, several properties of sand concrete including different percentages of 
TABle 1: Properties of ordinary Portland cement.

\begin{tabular}{lccc}
\hline Properties & Specific gravity & Initial setting time (min) & Final setting time (min) \\
\hline Results obtained & 3.21 & 90 & 190 \\
\hline
\end{tabular}

TABLE 2: Properties of fine and coarse aggregates.

\begin{tabular}{lcccc}
\hline Properties & Specific gravity & Water absorption $\%$ & Fineness modulus & Total surface area $\left(\mathrm{m}^{2}\right)$ \\
\hline Fine aggregate & 2.65 & 0.62 & 2.47 & 1.43 \\
Coarse aggregate & 2.68 & 0.40 & 4.01 & 1.34 \\
\hline
\end{tabular}

AGB were measured in [7]. Near 8\% improvement in compressive strength was obtained for an optimum percentage of AGB. While mere visual observation revealed a powerful effect of AGB against capillary diffusion, porosity and capillarity were found to vary consistently with compressive strength and exhibited a minimum where strength was highest. Air content monotonously decreases to a low minimum as AGB fraction is augmented. Workability was found to always increase with AGB content, which suggests a potential for use of AGB in self-compacting concrete. This is addressed in the more recent study in [8] in which it was reported that the so-called biopolymer (Arabic Gum) concrete provides longer setting times and more workability than ordinary concrete.

In continuation of the work in [7] the aim of the present study is to enhance the current knowledge on the influence of AGB on the physical and mechanical properties of ordinary concrete at various ages, namely, permeability, tensile strength, flexural strength, and elastic modulus.

\section{Experimental Work}

\subsection{Materials}

2.1.1. Concrete. As a preliminary to the investigation of the concrete properties a characterization of the ordinary Portland cement used was carried out first. The initial and final setting times of the cement were determined according to the Test Method for Time of Setting of Hydraulic Cement of the ASTM C191 Standard [9] using the Vicat Apparatus. The specific gravity was obtained using the Test Method for Density of Hydraulic Cement of the ASTM C 188 Standard [10]. All these properties were evaluated using three data points per measured quantity. The results are shown in Table 1.

Then, the granulometry of the sand and the coarse aggregates were determined using sieve analysis according to the ASTM C 136-96a Standard Test Method [11] for Sieve Analysis of Fine and Coarse Aggregates. The obtained sizes for sand were $10 \mathrm{~mm}, 4.75 \mathrm{~mm}, 2.36 \mathrm{~mm}, 1.18 \mathrm{~mm}, 600 \mu, 300 \mu$, and $150 \mu$. The coarse aggregates were composed of $40 \%$ over $20 \mathrm{~mm}$ and $60 \%$ between 20 and $10 \mathrm{~mm}$ grain size. The fineness modulus of aggregate was considered as the weighted average size of sieves counted from the finest. The surface areas for aggregate samples have been calculated following Panda et al. [12] based on percent pass for each sieve. The

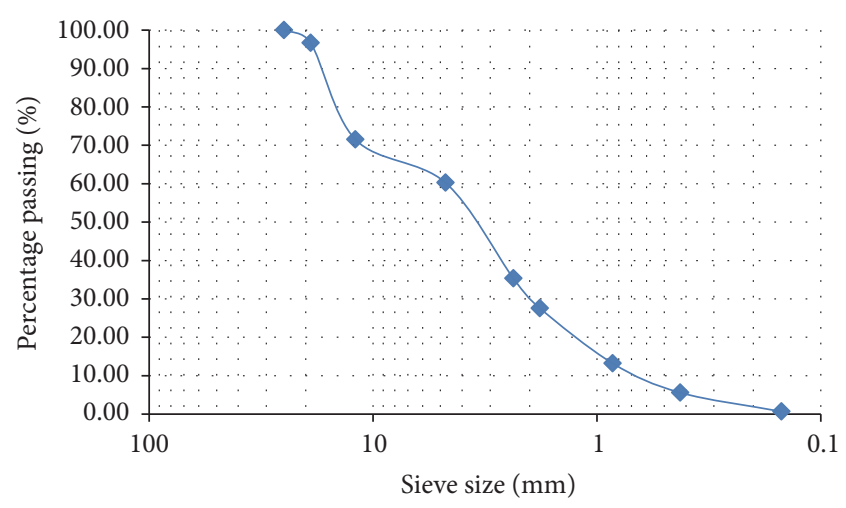

FIgURE 1: Size distribution of aggregate.

properties of fine and coarse aggregates are presented in Table 2.

The results of the sieve analysis tests are presented in Figure 1. They show that the distribution of the aggregate particle sizes conforms with the requirement stipulated in the ASTM C 136-96a standard [11] on the percentage passing and the maximum weight on each sieve.

2.1.2. AGB. Arabic Gum Biopolymer consists predominantly of volatile matter and a varying percentage of ash and is rich in metallic elements such as aluminum, iron, copper, zinc, and magnesium [1]. The physicochemical properties of AGB depend on the type and origin of the tree, exudation time, storage type, and climate. AGB is highly soluble in water and is characterized by a low viscosity compared to other gums. Finally, AGB can be dissolved in distilled water in concentrations beyond 50\% [2]. Alkalinity of AGB is confirmed by a measured $\mathrm{pH}$ of 8 for the AGB utilized in the present study using $781 \mathrm{pH} /$ Ion Meter-Metrohm at a room temperature of $20.6^{\circ} \mathrm{C}$.

\section{Method}

Concrete mixes were designed to determine the influence of $\mathrm{AGB}$ as additive to ordinary concrete with a water to cement ratio $W / C=0.5$. The $\mathrm{AGB}$ was integrated through the water in proportions within the range from 0 to $1.2 \%$ of the water weight. The range limit of $1.2 \%$ appeared to be sufficient to expose the relevant ranges of variation of the measured properties [7]. 


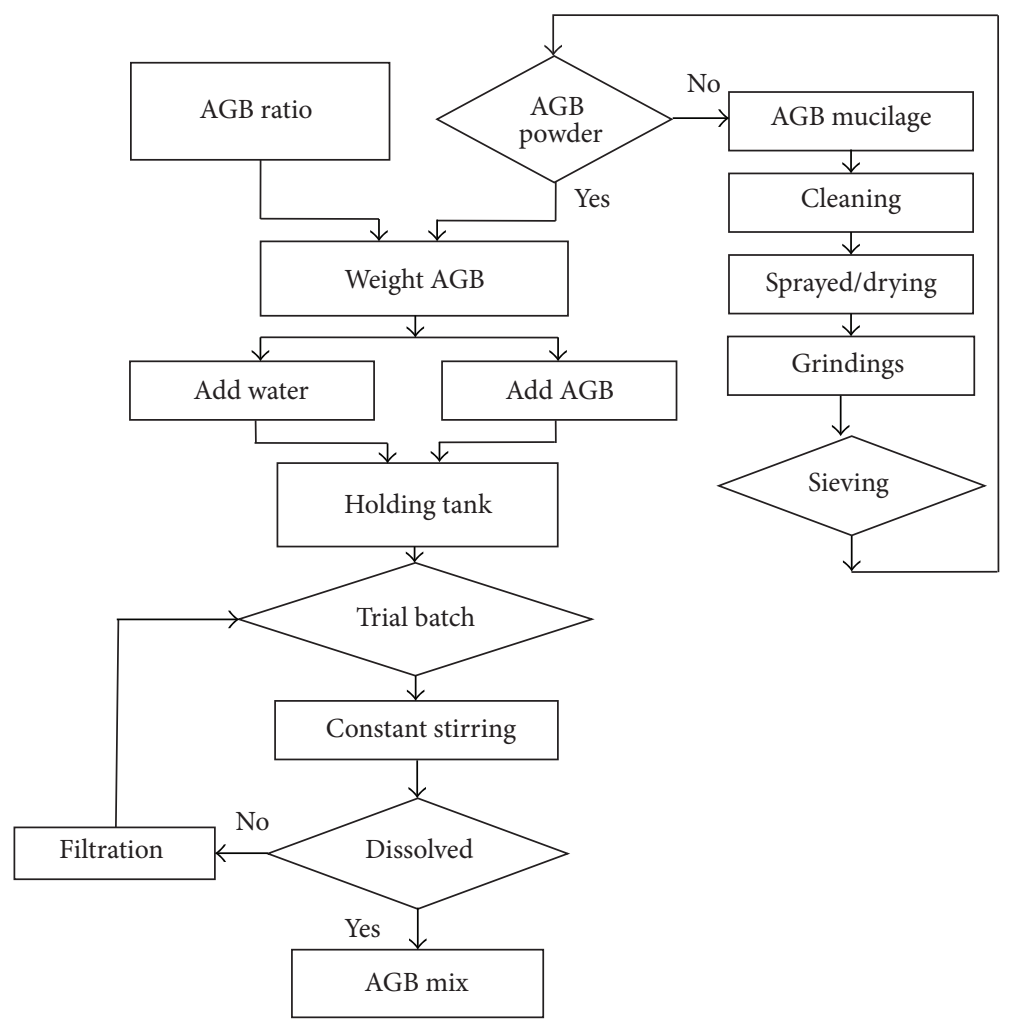

FIGURE 2: Mixing process of AGB.

For each AGB percentage the permeability and the flexural and tensile strengths were measured at various ages. In all experiments, and for each measured quantity, three concrete specimens were prepared and tested to obtain an averaged data point.

The permeability tests were conducted using a $100 \mathrm{~mm}$ diameter (ELE International Limited, London, UK) permeability cell designed in accordance with the Indian Standard Method [13] of Test for Permeability of Cement Mortar and Concrete.

The flexural tests were performed according to the ASTM C78-02 Standard Test Method [14] for Flexural Strength of Concrete (three-point bending). A beam with a cross section of $100 \times 100 \mathrm{~mm}$ and a length of $500 \mathrm{~mm}$ was used as a specimen for each test.

The tensile strength was evaluated based on the ASTM C496 Standard Test Method [15] for Splitting Tensile Strength of Cylindrical Concrete Specimens using a compression and bending machine and splitting cylindrical specimens with a height of $300 \mathrm{~mm}$ and $150 \mathrm{~mm}$ diameter.

The modulus of elasticity was deduced analytically from the compressive strength according to Section 8.5.1 of the ACI 318-08 Standard Building Code Requirements for Structural Concrete [16]. The compressive strength data used are results of compression tests performed by the authors and reported in [7].

All mixes were molded and covered with polyethylene sheets to prevent evaporation. After 24 hours, the specimens were demolded and carefully submerged in a curing tank. As per ASTM C192 Standard Practice for Making and Curing Concrete Test Specimens in the Laboratory [17], specimens were cured for 28 days and are then stored in a controlled environment at a temperature between $23^{\circ} \mathrm{C}$ and $28^{\circ} \mathrm{C}$ as stipulated in the ISO1920-3 [18] requirements for standard atmosphere for concrete materials testing.

After collection, the AGB granules are cleaned and dried using a spray and drying method. Then, they are dissolved in water directly or after being ground into powder using a special mechanical grinder and filtered through mechanical sieving. The powder form is useful for shortening the dissolving time but is not necessary.

The process of AGB preparation and treatment is explained in detail in [7]. In the present work the filtering was performed using $2 \mathrm{~mm}$ sieve size.

To prepare a solution with a chosen AGB to water ratio, sufficient quantities of water and AGB were weighed and then mixed together with the appropriate proportions in a holding tank. Constant stirring was applied to mix the solution until the AGB was totally dissolved in water. The mixing process is described in the flowchart in Figure 2.

\section{Test Description and Results}

4.1. Permeability. The permeability measuring system consists of a permeability cell composed of a metal cylinder with a porous stone at the bottom of the cell, a flange at the top, and a removable cover plate. A poly glass water reservoir is 


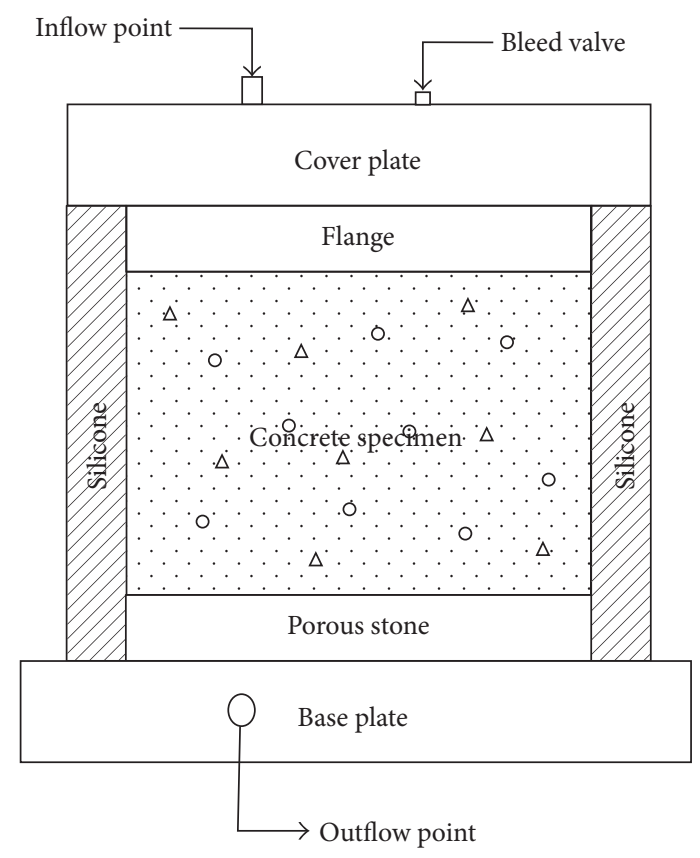

Figure 3: Setup for permeability cell.

connected to a deairing water system with a leak-proof hose in order to supply water to the permeability cell. Figure 3 shows the setup of the permeability cell.

The cylindrical test specimen dimensions are $80 \mathrm{~mm}$ for the diameter and $100 \mathrm{~mm}$ for the height. Each specimen is cleaned from dust and dried in the oven for 6 hours at a constant temperature of $105^{\circ} \mathrm{C}$ and then cooled down for two hours at a relative temperature between $20^{\circ} \mathrm{C}$ and $30^{\circ} \mathrm{C}$. Next, it is inserted and fixed into the permeability cell and a sealing layer is applied in the gap between the cell wall and the specimen.

The reservoir was filled with distilled water and the water was injected through the deairing system into the concrete sample until a steady state flow was established. From this moment, the pressure and the flow of water were recorded. Each measured quantity was evaluated based on three samples by retaining as a result the average of the three measurements. Figure 4 reports the permeability coefficient as a function of the AGB percentage. The permeability coefficient was calculated according to Darcy's formula:

$$
K=\frac{Q L}{t A H}
$$

where

$K$ is the coefficient of permeability in $\mathrm{cm} / \mathrm{sec}$,

$Q$ is the quantity of water in milliliters percolating over the entire period of test after steady state in $\mathrm{cm}^{3}$,

$A$ is the area of specimen base in $\mathrm{cm}^{2}$,

$t$ is the elapsed time in seconds,

$H$ is the applied pressure head in $\mathrm{cm}$ of water,

$L$ is the length of the specimen in $\mathrm{cm}$.

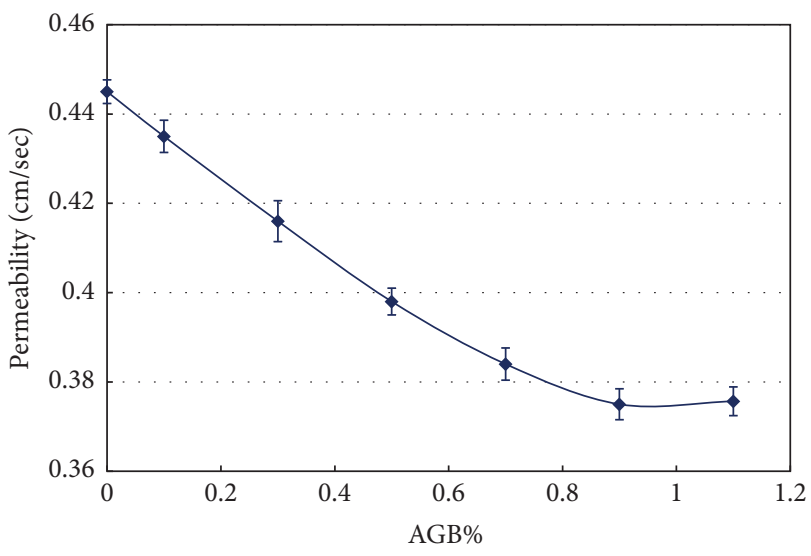

Figure 4: Permeability as a function of AGB content.

The permeability coefficient is seen to decrease due to AGB addition. The maximum improvement that could be achieved was $16 \%$ from 0.445 without $\mathrm{AGB}$ to 0.375 for an AGB percentage of $0.9 \%$.

4.2. Flexural Strength. Flexural strength was evaluated by applying the three-point bending method for simple beams according to the ASTM C78-02 Standard [14]. The test specimens were prepared using concrete containing different percentages of AGB. Three specimens were tested for each AGB percentage and the average of the three results was adopted as the value for flexural strength. The flexural strength is evaluated using the following formula stipulated in the above-mentioned ASTM C78-02 Standard [14]:

$$
F=\frac{P S}{b d^{2}}
$$

where

$F$ is the flexural strength of the concrete $(\mathrm{MPa})$,

$P$ is the maximum applied $\operatorname{load}(\mathrm{N})$,

$S$ is the span length $(\mathrm{mm})$,

$b$ is the specimen width $(\mathrm{mm})$,

$d$ is the specimen height $(\mathrm{mm})$.

Figure 5 presents the flexural strength as a function of the AGB percentage. The strength which was evaluated at $3.96 \mathrm{MPa}$ without $\mathrm{AGB}$ addition exhibits a maximum of 4.2 MPa for an AGB percentage between 0.7 and $0.8 \%$.

4.3. Tensile Splitting Strength. Tensile splitting strength was determined according to ASTM C496-96 Standard [15]. The cylindrical specimens were prepared using concrete mixes with various $A G B$ percentages with the provision of three specimens per AGB percentage. The splitting tensile strength for the concrete specimen was calculated using the following formula given by the ASTM C496-96 Standard [15]:

$$
T=\frac{2 P}{\pi l d}
$$




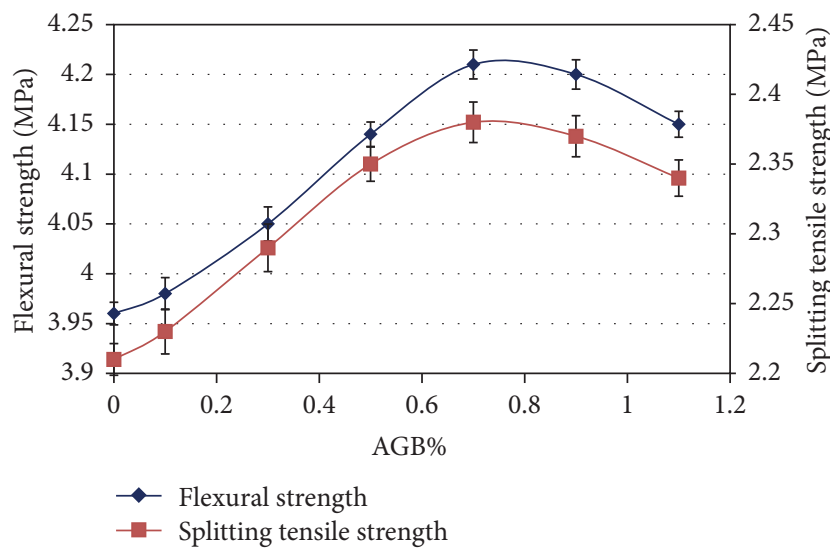

FIGURE 5: Flexural and tensile strength of concrete variation with AGB\%.

where

$T$ is the splitting tensile strength (MPa),

$P$ is the maximum applied load $(\mathrm{N})$,

$l$ is the specimen length $(\mathrm{mm})$,

$d$ is the diameter of the specimen (mm).

The results for the tensile splitting strength are plotted in Figure 5 as a function of AGB percentage. The splitting strength increases from 2.21 MPa without AGB to a maximum of 2.38 MPa for an AGB percentage of $0.7 \%$.

4.4. Modulus of Elasticity. The modulus of elasticity of concrete is determined indirectly from the compressive strength results, using the formula

$$
E_{c}=4700 \sqrt{f^{\prime}}
$$

where $E_{c}$ is the modulus of elasticity in GPa and ${f^{\prime}}_{c}$ is the compressive strength at 28 days in $\mathrm{MPa}$, recommended by the ACI 318-08 Code [16] for concrete with normal density and strength greater than $21 \mathrm{MPa}$ recommended by Zhu et al. [19]. The results are shown in Figure 6 for the elasticity modulus as a function of AGB percentage. The maximum of the modulus, $32.39 \mathrm{GPa}$, is attained at an AGB percentage of 0.9 , that is, a $4 \%$ increase resulting from the addition of AGB.

The test results for the studied properties are summarized in Table 3 with the corresponding AGB percentages.

\section{Discussion}

Permeability is a physical property that influences the durability of concrete. From a microstructural perspective it is influenced by the porosity, pore size, connectivity, and bonding. It is closely correlated with air content and capillarity. Hence, as expected from the porosity, capillarity, and air content results reported in [7], the plots presented in Figure 4 show a reduction in the coefficient of concrete permeability due to AGB addition. The minimum permeability is attained

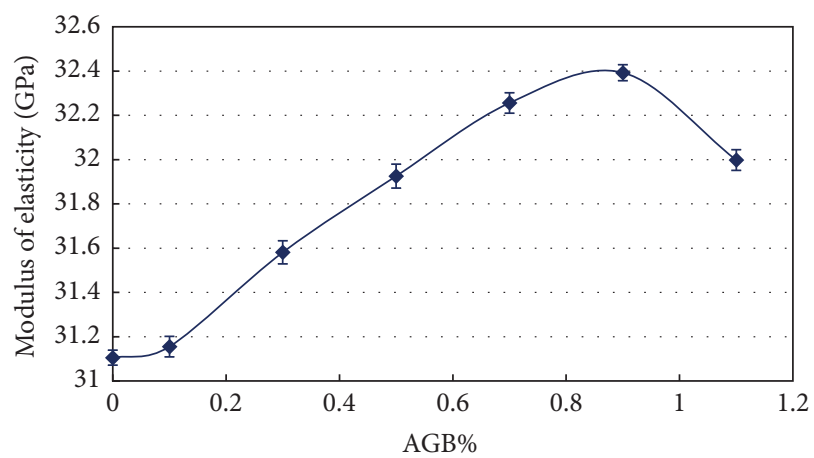

FIGURE 6: Concrete modulus of elasticity variation with AGB percentage.

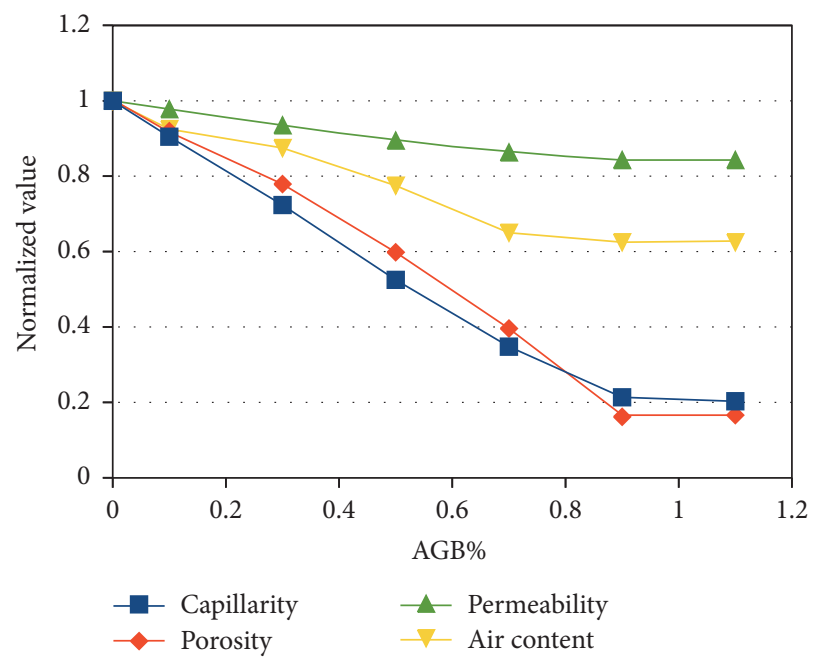

FIGURE 7: Variation of physical properties with AGB percentage (capillarity, porosity, and air content data [7]).

for $\mathrm{ABG}$ percentages above $0.9 \%$, corresponding to a relative change of $16 \%$ with respect to the mixture with plain water.

Figure 7 shows the variation of the four physical properties normalized each with respect to the value in the absence of AGB. It shows a common trend where the property decreases to a minimum as the AGB content is increased up to 0.9 to $1.1 \%$ and then remains nearly constant. More accurately, the permeability and the porosity reach their lowest point at the same percentage of 0.9 , whereas the capillarity and the air content attain their minimum at 1.1\% AGB content. This is in agreement with the known correlation between these properties that are affected by the fine particles of AGB that occupy the microscopic voids and tend to fill the internal pores of the concrete.

It is important to note that the effect of AGB on these physical properties is favorable to the durability of the material which is regarded as a significant merit of AGB.

On the other hand, the effects of AGB content on flexural and tensile strengths, presented in Figure 5, exhibit a maximum relative increase of near $7 \%$ which is close to the $8 \%$ increase observed in compressive strength [7]. These 
TABLE 3: Summary test results.

\begin{tabular}{|c|c|c|c|c|c|}
\hline AGB $\%$ & $\begin{array}{c}\text { Average of } \\
\text { permeability, } \\
\mathrm{cm} / \sec 10^{-7}\end{array}$ & $\begin{array}{l}\text { Average of } \\
\text { flexural } \\
\text { strength, } \\
\mathrm{MPa}\end{array}$ & $\begin{array}{l}\text { Average of } \\
\text { splitting tensile } \\
\text { strength, } \\
\mathrm{MPa}\end{array}$ & $\begin{array}{c}\text { Average of } \\
\text { compressive } \\
\text { strength }^{*}\left(f_{c}^{\prime}\right) \text {, } \\
\mathrm{MPa}\end{array}$ & $\begin{array}{c}\text { Average of } \\
\text { modulus of } \\
\text { elasticity, } \\
\mathrm{GPa}\end{array}$ \\
\hline 0 & 0.445 & 3.96 & 2.21 & 43.80 & 31.10 \\
\hline 0.1 & 0.435 & 3.98 & 2.23 & 43.94 & 31.15 \\
\hline 0.3 & 0.416 & 4.05 & 2.29 & 45.15 & 31.58 \\
\hline 0.5 & 0.398 & 4.14 & 2.35 & 46.14 & 31.92 \\
\hline 0.7 & 0.384 & 4.21 & 2.38 & 47.10 & 32.25 \\
\hline 0.9 & 0.375 & 4.20 & 2.37 & 47.50 & 32.39 \\
\hline 1.1 & 0.375 & 4.14 & 2.34 & 46.35 & 31.99 \\
\hline
\end{tabular}

${ }^{*}$ From [7].

relative improvements are coherent given the proportionality of compressive and tensile strengths.

The flexural and indirect splitting strengths are distinct measures of tensile strength. As expected, they were significantly different in magnitude; however, they were found to follow the same pattern of variation as a function of AGB percentage. This is explained by their linear correlation illustrated by the relationship $F=1.02 T+1.48(\mathrm{MPa})$ proposed in [20]. The flexural strength deduced from the splitting test results using the above relationship is found to be between $5 \%$ and $7 \%$ lower than the measured flexural strength as shown in Figure 5.

Finally, the maximum relative improvement in the modulus of elasticity (Figure 6) due to AGB addition is $4 \%$. This value is expected since the modulus, deduced analytically through (4), is proportional to the square root of the compressive strength.

For the concrete properties studied in the present work and those reported in [7], apart from workability, the effect of AGB has systematically been on the desirable side. This highlights the merit of AGB in comparison with other admixtures such as foundry sand and rice husk ash which tend to be favorable to one property at the expense of others.

Nonetheless, the best obtained improvements seem to be unsurpassable within the presented protocol. Further investigation is needed to possibly raise the performance. This would require modification of the protocol such as combining AGB with chemical agents. As for workability, it has been reported $[7,8]$ to continue to increase with even large percentages of AGB content whereas the desired slump depends on the application. When the setting time is not a concern and strength is not affected, workability is desirable and in the case of self-compacted concrete it is even essential.

\section{Conclusion}

Arabic Gum Biopolymer (AGB) is a vegetal product that is naturally grown in West Africa, most abundantly in Sudan at low cost. Its numerous attractive physical and rheological properties make it useful in many industrial applications. In the present work the effect of including AGB as an admixture on the tensile and flexural strength and permeability of concrete has been investigated within an ongoing effort to assess the role of AGB in improving the performance of concrete with the end goal of promoting the use of AGB as a sustainable natural product in the construction sector. Series of tests have been conducted using concrete samples at a water to cement ratio of 0.5 with various percentages of AGB to determine the percentages that achieve the best performance for each studied property. The test results showed a $16 \%$ reduction in the coefficient of permeability of concrete for an optimal AGB weight fraction of $0.9 \%$, which implies a significant improvement in durability. Flexural and tensile strengths were found to exhibit a maximum increase near $7 \%$ for an AGB percentage in the vicinity of $0.7 \%$. On the other hand, the modulus of elasticity was estimated to reach $4 \%$ increase with addition of AGB. These improvements, together with those reported previously with regard to other properties such as compressive strength, capillary diffusion, and workability, provide evidence of the merits of AGB as an additive to concrete mix in pursuit of better concrete performance and more sustainability in concrete technology. Whether further enhancements can be achieved in these properties and the effect of AGB on other concrete properties and its dependence on the water to cement ratio are issues that remain to be addressed in future investigations.

\section{Conflicts of Interest}

The authors declare that there are no conflicts of interest regarding the publication of this paper.

\section{Acknowledgments}

The authors would like to express their appreciation to the Faculty of Civil Engineering, UTM, for the support they provided to this work, and their gratitude to Dr. Sadok Mehrez for his kind assistance.

\section{References}

[1] K. A. Karamalla, N. E. Siddig, and M. E. Osman, "Analytical data for Acacia senegal var. senegal gum samples collected between 1993 and 1995 from Sudan," Food Hydrocolloids, vol. 12, no. 4, pp. 373-378, 1998. 
[2] R. Randall, G. Phillips, and P. Williams, "The role of the proteinaceous component on the emulsifying properties of gum arabic," Food Hydrocolloids, vol. 2, no. 2, pp. 131-140, 1988.

[3] D. Verbeken, S. Dierckx, and K. Dewettinck, "Exudate gums: occurrence, production, and applications," Applied Microbiology and Biotechnology, vol. 63, no. 1, pp. 10-21, 2003.

[4] A. M. Saleh, High-Strength Concrete and the Resistance through the Improvement of Natural Additions, International University of Civil Engineering, Moscow, Russia, 2001.

[5] C. L. Hwang, A. T. Bui, and C. T. Chen, "Effect of rice husk ash on the strength and durability characteristics of concrete," Construction and Building Materials, vol. 25, no. 9, pp. 37683772, 2011.

[6] T. R. Naik and B. W. Singh S.S.Ramme, "Performance and leaching assessment of flowable slurry," Journal of Environmental Engineering, vol. 127, no. 4, pp. 359-368, 2001.

[7] A. M. Mohamed, M. H. Osman, and H. Smaoui, "Effect of arabic gum biopolymer on fresh and hardened concrete properties," International Journal of Civil and Structural Engineering, vol. 6, no. 3, pp. 187-194, 2016.

[8] P. W. Zakka, O. F. Job, and N. A. Anigbogu, Ecological selfcompacting concrete using Gum Arabic as a plasticizer, Department of Building, University of Jos, Nigeria, 2015.

[9] ASTM, Standard Method of Test for Time of Setting of Hydraulic Cement by Vicat Needle, ASTM C191-04a, Philadelphia, PA, USA, 2006.

[10] ASTM, Standard Test Method for Density of Hydraulic Cement, ASTM C188, Philadelphia, PA, USA, 2003.

[11] ASTM, Standard Method of Test for Sieve Analysis of Fine and Coarse Aggregates, ASTM C136-96a, Philadelphia, PA, USA, 2007.

[12] R. P. Panda, S. S. Das, and P. K. Sahoo, "An empirical method for estimating surface area of aggregates in hot mix asphalt. of Traffic and," Transportation Engineering, vol. 3, no. 2, pp. 127136, 2016.

[13] IS, Method of test for permeability of cement mortar and concrete, IS 3085, Bureau of Indian Standard, New Delhi, India, 1965.

[14] ASTM, Standard Test Method for Flexural Strength of Concrete Using Simple Beam with Third-Point Loading, ASTM C78-02, Philadelphia, PA, USA, 2002.

[15] ASTM, Standard Test Method for Splitting Tensile Strength of Cylindrical Concrete Specimens, ASTM C496-96, Philadelphia, PA, 2004.

[16] ACI, Standard Building Code Requirements for Structural Concrete, ACI 318-08, Farmington Hills, MI, 2008.

[17] ASTM, Standard practice for making and curing concrete test specimens in the laboratory, ASTM C192, Philadelphia, PA, USA, 2007.

[18] ISO, Testing of Concrete -Part 3: Making and curing test specimens, ISO 1920-3, 2004.

[19] P. Zhu, G. S. Jay, and R. B. Vijay, "Fracture properties of geopolymer paste and concrete," Magazine of Concrete Research, vol. 63, no. 10, pp. 763-771, 2011.

[20] G. M. Hammitt, Concrete Strength Relationships, US Army Corps of Engineers, Waterways Experiment Station, Vicksburg, Miss, USA, 1971. 


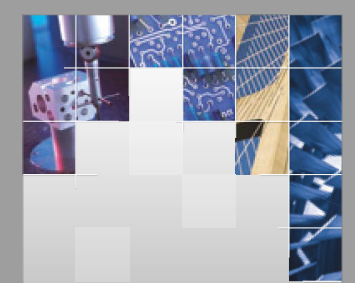

\section{Enfincering}
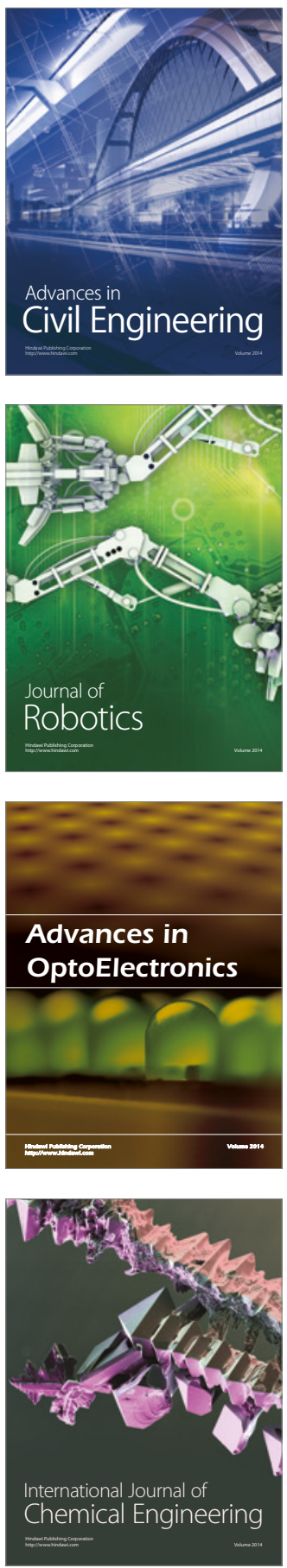

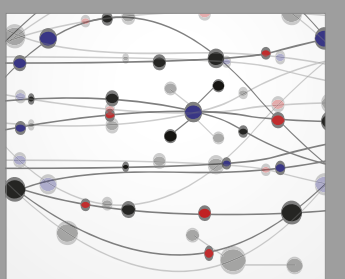

The Scientific World Journal

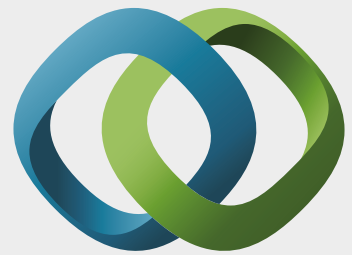

\section{Hindawi}

Submit your manuscripts at

https://www.hindawi.com
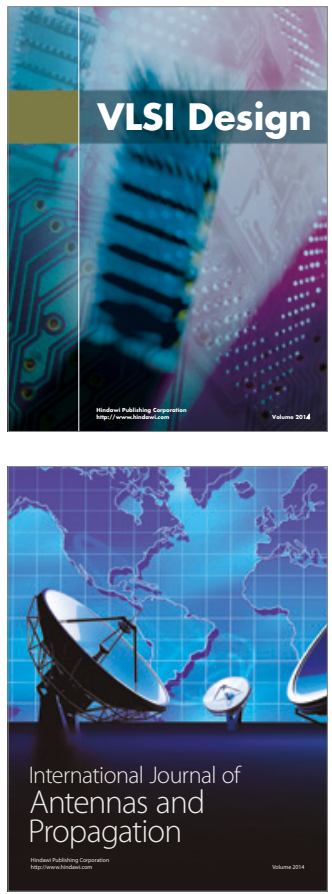

\section{Rotating}

Machinery
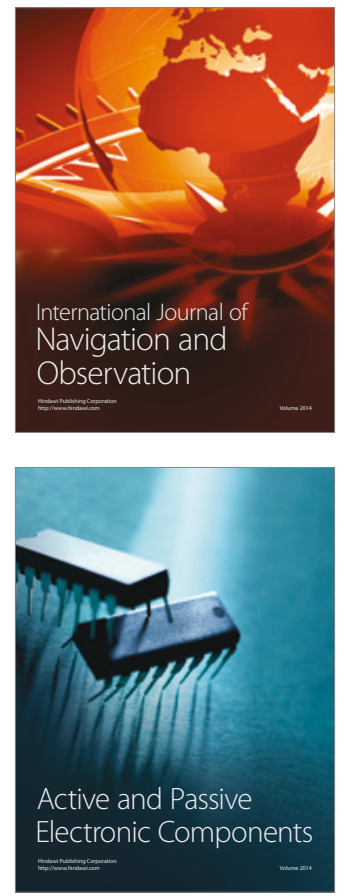
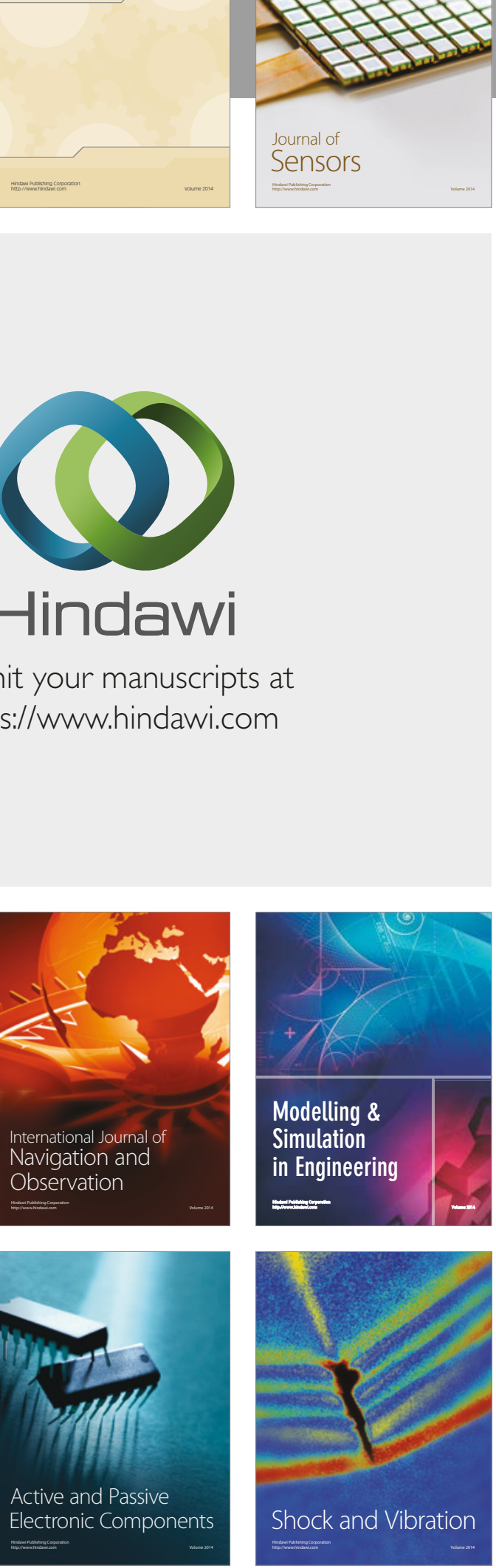
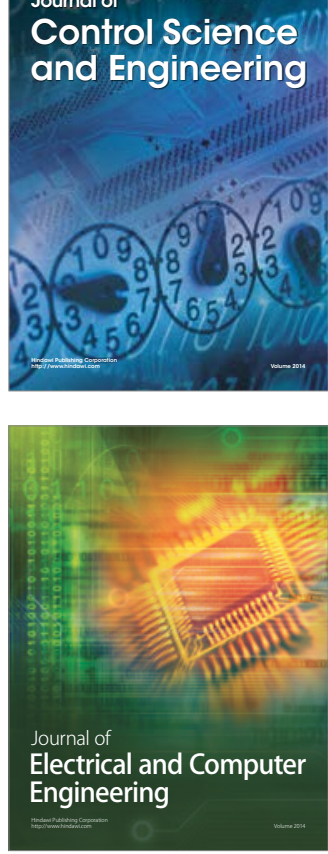

Distributed

Journal of

Control Science

and Engineering
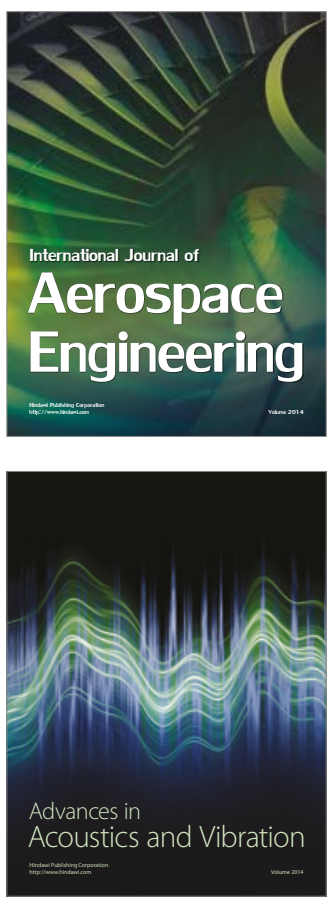

Sensor Networks 